\title{
Haitian history and culture A selection of online resources
}

W hen searching for and examining the many online resources available regarding Haitian history, it is critical to recognize the various names that present-day Haiti has had in the past, including Hispaniola, SaintDomingue, and Ayiti, in order to clarify what historical events occurred at what time.

It is similarly critical to use appropriate keywords. For example, for information regarding the era of Spanish colonization from 1492 to 1679 , researchers can use the term Hispaniola, although such will return results referring to not only present-day Haiti, but also the present-day Dominican Republic, since both countries form the island once known as Hispaniola. The history of native populations such as the Arawaks, including the Taino, and the Caribs can also be found using the term Ayiti, although some data are liable to appear in Haitian Creole. Researchers should use Saint-Domingue if they seek information on the history of that island during the French occupation and colonial period from 1625 to 1804; however, they need to be aware of the term's various spellings and the fact that some writers use Santo Domingo instead. Lastly, when searching for individuals of Haitian descent, researchers should know that such individuals might be misclassified as being of another ethnicity or from another culture.

A particularly useful source for historical research is YouTube. It is not only excellent for individual researchers, but also an excellent tool for the classroom. Other than music, YouTube offers many resources such as historical documentaries, programs, and biographical videos on notable individuals.
The site contains thousands of videos-many from reputable, reliable sources such as PBS-on Haiti's architecture, food, history, language, and music, among other aspects of Haitian life, history, and culture, which educators can use in their teaching.

Of the numerous free websites available to assist the study of Haitian history and culture, the following represent a small selection chosen because they are user friendly and packed with data that can direct researchers to other resourceful websites.

\section{Architecture}

- Citadelle Laferrière website. Citadelle Laferrière, a mountaintop fortress in northern Haiti, is a major symbol of Haitian pride, determination, and freedom. Dedicated solely to the Citadelle's history, the website offers a particularly fascinating account of the construction of the architectural wonder and an image gallery. Access: http://www. citadellelaferriere.com/.

- Citadelle Laferrière. This YouTube video offers a virtual tour of Citadelle Laferrière, in which viewers can observe the exterior and interior of the fortress, along with the SansSouci Palace in the town of Milot. Although the video offers no host, none is necessary, for the fortress speaks for itself. The video occasionally presents historical facts on the screen, and

Marjorie Charlot is assistant librarian at Touro College and reference assistant at Long Island University, email: marjorie.charlot@liu.edu

(c) 2017 Marjorie Charlot 
the captions are no longer than two or three sentences. The video was filmed by Harold Estime and Rene Durocher, edited by Harold F. Estime, and set to Beethoven's "Moonlight Sonata." Access: https://www.youtube.com /watch?v=j0h1CeqIAIo.

- Haiti's Gingerbread Houses. TIME's website includes a slideshow of 11 images taken by William Daniels of Haiti's architectural treasures, the Gingerbread Houses, with captions that state the age of each structure and its location, as well as photographs of the interiors. Access: http://content.time.com /time/photogallery/0,29307,2004148,00.html.

\section{Blogs}

- Kreyolicious. This blog offers insights into Haiti's past and present by showing visitors images of Haitian clothing, Haitian home designs, and renowned Haitians. It also offers resources on Haitian authors and artists of various genres. Access: http:// kreyolicious.com/.

\section{Country profile: Quick facts and demographics}

- CIA World Factbook. Provided in the Central Intelligence Agency's (CIA) library section of its website, the CIA World Factbook is part of the public domain, may be used for free, and offers an abundance of statistical and factual data about countries worldwide, including about their populations, key historical events, and national flags. Users need only to click on the region or continent and select the country of interest. Access: https://www.cia. gov/library/publications/the-world-factbook/.

- Haiti Country Profile. The website of BBC News offers quick facts about Haiti and even a profile of former leaders President Michel Martelly and Prime Minister Laurent Lamothe. It also provides a general timeline of major disasters, starting with the earthquake that devastated Port-au-Prince in 1770 and ending with the 2011 cholera outbreak. Access: http://news.bbc.co.uk/2/hi/americas /country_profiles/1202772.stm\#facts.

- Library of Congress. During the 1940 s and 1950s, the Federal Research Division of the Library of Congress started publishing books on countries worldwide as part of the Country Studies/Area Handbook Series. Once available to the public in hard copy only, the series has now been digitalized and is accessible online. The Library of Congress maintains a collection of 80 of the books on its website. The volume on Haiti is titled Dominican Republic and Haiti: Country Studies, which gives a profile of both countries of Hispaniola. Access: https://www.loc.gov /item/2001023524/.

\section{History}

- The Digital Library of the Caribbean. Founded in 2004, this website offers resources about the Caribbean and circum-Caribbean from archives, libraries, and private collections. Although an open digital library, to access some features, users need to become members by registering for a free MydLoc account. Access: http://www.dloc.com/dloc.

- Haiti: Table by Bob Corbett. In this section of Bob Corbett's website, hosted by Webster University, a table of contents lists various resources and essays by several authors on a range of topics. Professor emeritus of philosophy at Webster, Corbett has assembled countless materials for researchers investigating the history of Haiti, including 110 book reviews and arts, music, and dance resources. Access: http://faculty.webster.edu /corbetre/haiti/haiti.html.

- Latin American Network Information Center. Launched in 1992, the Latin American Network Information Center is part of the Lozano Long Institute of Latin American Studies and Benson Latin American Collection at the University of Texas-Austin. The site provides an interactive map of the regions of Latin America and the Caribbean that are searchable by clicking. A search for "Haiti" will return roughly 455 items. The site also provides materials on a range of subjects, and some resources link to other websites. Access: http://lanic.utexas.edu/.

- World History Archives. Created by Hartford Web Publishing, this website "offers documents to support the study of world his- 
tory from a working-class and non-Eurocentric perspective." The site is set up into five categories: the World, the Americas, Asia and Oceania, Africa, and Europe. Users simply select the region and country of choice. The section on Haiti is titled "Haiti Archives" and includes eight listings. Access: http://www.hartford-hwp.com /archives/.

\section{Immigrants}

- The African-American Migration

Experience. Presented by the Schomburg Center for Research in Black Culture, this website hosts an index of information on various sorts of migration and includes two migration sections about Haitians: "Haitian Immigration: 18th and 19th Centuries" and "Haitian Immigration: 20th Century." It not only offers resources on Haitian migration to New Orleans, Louisiana, but also shows the impact that Haitian immigrants have had on U.S. history. Users can also browse images, maps, and digitized historical documents. Access: http://www.inmotionaame.org /migrations/index.cfm.

\section{Language}

- Alfabè Creole (Creole alphabet). A collaboration between Massachusetts Institute of Technology Linguistic Professor Michel DeGraff and recognized Creole advocate Mandaly Louis-Charles, this two-part video features the first Haitian Creole alphabet songs as a tool for teaching Creole. Access: https://www. youtube.com/watch? $\mathrm{v}=$ EnMSGPSYqqI\&list =PLO0aSAhMoiIjFOcw_3fpoHRRXhqWPKS 1T\&index $=4$.

- Creole: The National Language of

Haiti. This site offers a history of the origins of the Creole language. Author Albert Valdman explains the verbs and nouns of the language and shows tables that compare the various words in Creole, French, and English. Access: http://www.indiana.edu/ creole /creolenatllangofhaiti.html.

- Haitian Creole. Created by the UCLA Center for World Languages, this website is a profile of the creole language as spoken by numerous speakers with linguistic affilia- tions. It explains how and why the language was developed. Access: http://lmp.ucla.edu /Profile.aspx?menu=004\&LangID=2.

\section{Timelines}

- Europe and Saint-Domingue. This interactive timeline by the Choices Program, a nonprofit organization based at Brown University, contains images rarely seen and guides visitors through the early history of Saint-Domingue and the involvement and impact of France and North America in Haitian history both before and after the revolution. Among other things, it provides a video on 1794, when slavery was abolished in Haiti. Access: http://www.choices.edu/resources /activities/haiti/timeline.html.

- History of Haiti, 1492-1805. Assembled by Kona Shen at Brown University, this website offers a timeline of major historical periods, beginning with 1492, when Christopher Columbus landed on Hispaniola, and continuing on to 1697, when Spain handed over the western third of the island to France with the Treaty of Ryswick. The timeline ends in 1805, a year after Haiti's independence. The timeline also offers images of key figures, maps, and battle scenes, among other things. Access: http://library.brown.edu/haitihistory/.

- U.S.-Haiti (1804-2005). Run by the Center for Grassroots Oversight, funded by the Global Center, a 501(c) 3 nonprofit organization, this timeline considers the history of the United States in Haiti, especially in terms of political impact. The site is interactive, and each year is scalable for a broader context. Access: http://www.historycommons.org /timeline.jsp?timeline $=$ haiti

\section{YouTube}

- Creole Common Routes: SaintDomingue (Haiti)-Louisiana. This series includes four short videos (i.e., approximately 7:00 each) on the history and relationship of Saint-Domingue and New Orleans, Louisiana. The uprising in Haiti and migration of people from Saint-Domingue to Cuba and New Orleans are addressed, as are the contributions of Haitians to Louisiana. The 
video additionally touches upon how the Louisiana Purchase affected the lives of people living in the territory at the time. Access: https:// www.youtube.com/watch?v=yb8Ig5IMhZU\&list $=$ PLaZDlkL6Ra7NhTOX0GmhiPGlkbJ5NWdtt \&index $=1$.

- Greatest Black Emancipation: The Haitian Revolution (1791-1803). This video (40:56) examines the history of Haiti and the Haitian Revolution, which ended in the emancipation of African slaves in Haiti. It also provides a timeline of Haitian history from pre-1492 to 1804 and describes the impact of the Haitian Revolution on slavery in the Americas and the effects of the Louisiana Purchase. Access: https://www.youtube.com $/$ watch? $=$ Sqh1h8SEcEc.

\section{- Egalite for All: Toussaint Louver-} ture and the Haitian Revolution (PBS, 2009). This video $(55: 22)$ describes events on Saint-Domingue that precipitated the rise of Toussaint Louverture. It showcases the early history and system of slavery on Saint-Domingue, with a particular focus on race and the racial mixing of Africans and
Europeans there that prompted a system for cataloging the various shades of skin color in 110 categories according to drops of African blood. Such intermixing and categorization eventually prompted those of mixed race to seek equal rights. Access: https://www. youtube.com/watch?v=IOGVgQYX6SU.

\section{- Haiti and the Dominican Republic.}

The Roots of Division. This video (51:25) is the first of a four-part documentary titled Black in Latin America, each episode of which showcases the African heritage of Brazil, Mexico, Peru, the Dominican Republic, Haiti, and Cuba. Originally aired on PBS in 2011, the episodes explore race and identity in Latin America. Episode 1, which covers Haiti and the Dominican Republic based on Henry Louis Gates Jr.'s Black in Latin America, explains the histories of both countries. Access: https://www.youtube.com /watch?v=6RlG4b3LV9o.

\section{Note}

1. World History Archives, accessed March 2, 2017, www.hartford-hwp.com/archives/43 /index.html $\boldsymbol{n}$

\section{Spring 2017 ACRL-Choice webinars}

ACRL-Choice webinars connect academic and research librarians with content and service providers, publishers, authors, and other experts. This spring, the webinar program presents a wide variety of subjects and experts.

April 6: "From Video Usage to Engagement to Impact-Charging Ahead" with Kathleen McLellan, senior product manager, David Parker, senior vice president of editorial and licensing, and Pete Ciufetti, vice president of product development, all of Alexander Street, sponsored by Alexander Street, a ProQuest Company.

April 20:"Experimental Publishing at the Intersection of Science,Art, and Technology" with Roger Malina, distinguished professor of art and technology and professor of Physics, University of Texas-Dallas, and Jon
Ippolito, professor of new media and codirector of the Still Water Lab and Digital Curation Program, University of Maine, sponsored by The MIT Press/.

April 26: "Connect the Library to the Lab" with Gerry Sawchuk, senior director, business, science, analytics-academic, Gale, sponsored by Gale, a Cengage company.

May 2: "Designing Academic Libraries for Modern Human Behavior" with Jeffrey Hoover of Tappé Architects and Joe S.Agati, a formally trained industrial designer with Agati Furniture, sponsored by Tappé Architects and Agati Furniture.

For more information on upcoming ACRL-Choice webinars, please visit www. choice360.org. To discuss becoming an ACRL-Choice webinar sponsor, contact Pam Marino at pmarino@ala-choice.org. 